\title{
AVALIANDO O PROGRAMA MUTIRÃO PELA INCLUSÃO DIGITAL EM BUSCA DE ALTERNATIVAS METODOLOGICAS PARA PROJETOS DE EXTENSÃO UNIVERSITÁRIA
}

\author{
EVALUATING THE "MUTIRÃO PELA INCLUSÃO DIGITAL" \\ PROGRAM IN SEARCH OF METHODOLOGICAL \\ ALTERNATIVES FOR UNIVERSITARY EXTENSION PROJECTS
}

Adriano Canabarro Teixeira* Amilton Rodrigo de Quadros Martins**

\begin{abstract}
Resumo: A presente pesquisa está vinculada ao programa de extensão "Mutirão pela Inclusão Digital", da Universidade de Passo Fundo (UPF), e tem como objetivo compreender as potencialidades e as limitações da metodologia utilizada nas Oficinas de Informática e Cidadania nele oferecidas sob o prisma teórico das Arquiteturas Pedagógicas, propostas por Carvalho, Nevado e Menezes (2007). O método utilizado para a condução da referida avaliação caracteriza a pesquisa como qualitativa de cunho exploratório, e a coleta de dados primários foi feita por meio de uma triangulação de instrumentos. Os sujeitos da pesquisa figuraram como 31 alunos da educação infantil, dois professores e quatro monitores das referidas Oficinas. Os principais resultados permitem concluir que a metodologia em foco está em convergência com o conceito das Arquiteturas Pedagógicas, sendo uma alternativa potente de transformação social por meio de atividades de extensão da Universidade na comunidade.
\end{abstract}

Palavras chave: Arquiteturas Pedagógicas; Aprendizagem; Comunicação; Participação.

\begin{abstract}
This research is linked to the Outreach Program "Joint Effort for Digital Inclusion" from the University of Passo Fundo (UPF). It aims to understand the potentialities and limitations of the methodology used in Informatics and Citizenship Workshops offered under the theoretical perspective of Pedagogical Architectures proposed by Carvalho, Nevado and Menezes (2007). The evaluation method used in the research is characterized as qualitativeexploratory and the primary data collection was done through the triangulation of instruments. The research participants included thirty-one preschoolers, two schoolteachers and four monitors of the aforementioned workshops. The main results suggest that the methodology adopted in the study is in accordance with the concept of Pedagogical Architectures, which is a powerful alternative for social transformation through university outreach activities carried out in the community.
\end{abstract}

Keywords: Pedagogical Architectures; Learning; Communication; Participation. 


\section{Introdução}

Dentre os importantes papéis da extensão universitária, está a transformação da sociedade a partir do conhecimento gerado dentro das instituições de ensino superior. É fundamental que essas ações junto à comunidade contribuam para a transformação dela própria e, em uma análise mais ampla, auxiliem na formação de cidadãos que tenham condições de modificar o contexto social no qual se encontram.

Os avanços tecnológicos na área da informática no século XXI marcam a vida das pessoas de forma significativa. As tecnologias digitais estão presentes em vários segmentos da sociedade e constituem elementos definidores do que se chama de cidadão do século XXI, aquele capaz de apropriar-se dos diferentes dispositivos tecnológicos em uma perspectiva de produtor e não de mero usuário.

Entretanto, verifica-se a dificuldade de os ambientes educacionais formais fornecerem experiências significativas e disruptivas de acesso a essas tecnologias para seus alunos. Tal percepção ganha força ao se considerarem os dados da pesquisa realizada no âmbito do projeto "Nossa Escola em (re) construção", desenvolvida pelo Porvir/Instituto Inspirare, e publicada na Folha de São Paulo, em 22 de setembro de 2016, que contou com a participação de 132 mil jovens entre 13 e 21 anos de todas as regiões do país. Os entrevistados apontaram que desejam uma escola com currículo mais diversificado e flexível, em que se aprenda com atividades práticas e tecnologias digitais, em espaços físicos dinâmicos e variados (FOLHA DE SÃO PAULO, 2016).

Nesse sentido, é papel proeminente da universidade realizar ações junto à comunidade no sentido de explorar novos horizontes de capacitação e formação de sujeitos capazes de apropriar-se de forma crítica, criativa e efetiva das tecnologias digitais para o seu desenvolvimento. Tal papel ganha ainda mais relevância por ser locus de pesquisas de ponta em relação ao desenvolvimento e à apropriação de tecnologias digitais na educação, bem como a exploração de possibilidades metodológicas diferenciadas, muitas vezes inviável em contextos e espaços formais de ensino.

Nessa perspectiva, esta pesquisa foi realizada no âmbito das Oficinas de Informática e Cidadania oferecidas pelo Programa de Extensão Mutirão Pela Inclusão Digital, vinculado ao Grupo de Pesquisa em Cultura Digital (Gepid), do curso de Ciência da Computação da Universidade de Passo Fundo (UPF). O programa possui uma proposta metodológica própria que busca, sobretudo, fomentar o protagonismo dos indivíduos, pois considera que o processo de aprendizagem se dá a partir da vivência de experiências, da ação, interação e reflexão do sujeito sobre o contexto no qual está inserido. Ainda, tem por mote possibilitar um processo de apropriação das tecnologias de rede por parte de camadas excluídas da sociedade.
Em funcionamento desde 2004, o Programa atende anualmente, e de modo concomitante, uma média de quatro turmas formadas por alunos, no princípio apenas do Ensino Fundamental, hoje também da Educação Infantil, advindos da rede municipal de Passo Fundo, através das Oficinas de Informática e Cidadania. As oficinas se propõem a habilitar as crianças ao uso de ferramentas tecnológicas e a autoria em diversos formatos. Com periodicidade semanal e com duração de 3 horas, ocorrem nos laboratórios de informática da Universidade de Passo Fundo, sob a responsabilidade de 4 monitores ( 1 do curso de Pedagogia e 3 dos cursos da área de Tecnologia da Informação, além dos professores da instituição de origem dos alunos).

O tema gerador das oficinas é definido anualmente e, posteriormente, ressignificado de acordo com os interesses e a realidade dos estudantes, dando origem a subtemas. Com tais delineamentos, desenvolvem-se nas Oficinas, de modo geral, atividades de autoria, envolvendo a construção de materiais hipermidiais (como vídeo, áudio, texto e imagem), de acordo com os subtemas e as ferramentas tecnológicas definidas por cada grupo. Frisa-se, nessa direção, que cada um desses trabalha com apenas uma tecnologia diferenciada dentro do tema gerador vídeos, áudio, texto e imagem -, para que, ao término de cada ciclo de atividades, cada grupo apresente sua produção aos demais.

Assim organizada, a metodologia adotada pelo projeto propõe dois encontros iniciais para adaptação dos estudantes, que antecedem as práticas e têm por objetivo ambientar os participantes ao funcionamento das oficinas e às ferramentas e ambientes digitais. A partir de tais encontros e da definição do tema das Oficinas, as práticas são constituídas por uma sequência de três modalidades de encontros (Conhecendo, Construindo, Socializando) que se repetem no decorrer do ano e de acordo com a evolução das turmas.

$\mathrm{Na}$ modalidade Conhecendo, com geralmente uma única oficina, faz-se uma sondagem dos conhecimentos prévios dos alunos sobre o subtema, partindo das discussões do grande grupo, através da proposição de perguntas que os desafiam a pensar propostas de materiais digitais de acordo com as tecnologias definidas para os grupos. A modalidade Construindo, por sua vez, tem a duração de dois ou mais encontros, e envolve o desenvolvimento de habilidades de autoria dos alunos utilizando as tecnologias digitais. É importante destacar que, no decorrer do ano, os estudantes participam de um rodízio entre as tecnologias com as quais se trabalha, a fim de explorarem todas as diferentes possibilidades tecnológicas.

Por fim, os encontros da modalidade Socializando, geralmente com a duração de uma única semana, os grupos apresentam suas produções aos demais, através de ferramentas de comunicação síncrona. Nesse contexto, a tomada de decisão é 
essencial, pois, para socializar o que realizaram, precisam fazer opções e negociações internas, levando em consideração as condições e as transformações que floresceram no decorrer dos encontros.

A Figura 1 representa como esta estratégia de grupos, os tipos de encontros $\mathrm{e}$ as tecnologias utilizadas são implementadas.

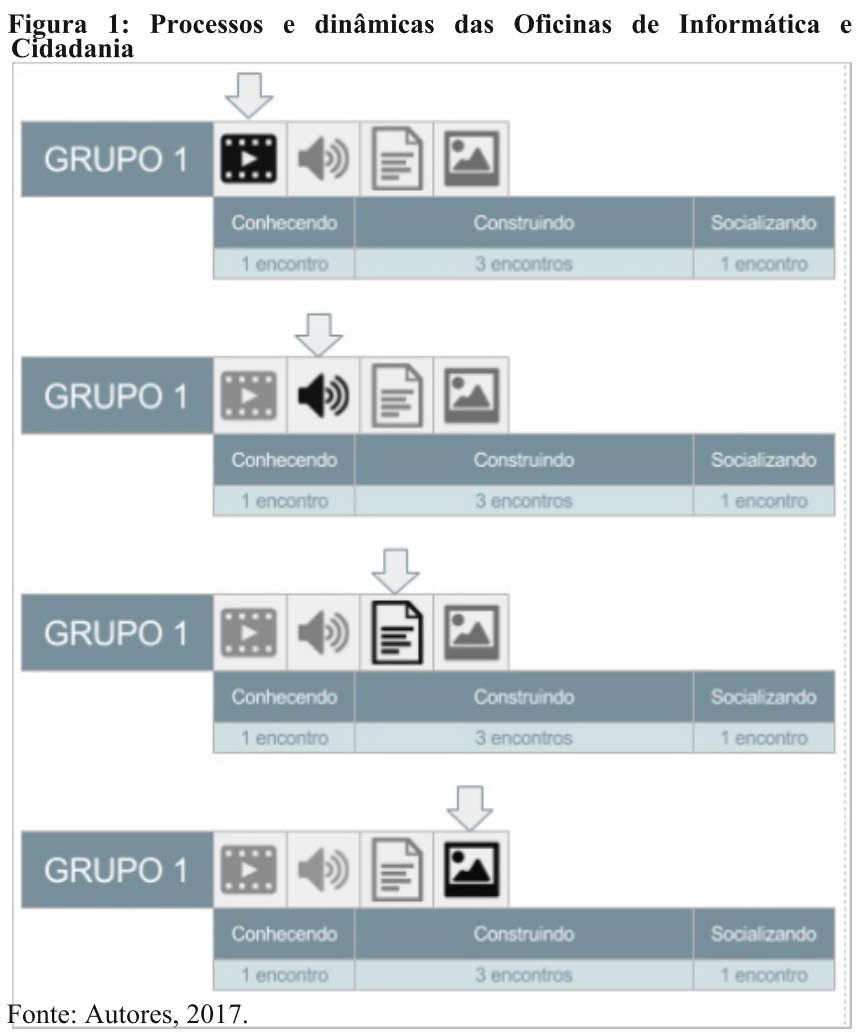

Diante da exposição da metodologia utilizada nas Oficinas de Informática e Cidadania oferecidas pelo Programa de Extensão Mutirão pela Inclusão Digital, adota-se, como parâmetro de análise, o conceito de Arquiteturas Pedagógicas, proposto por Carvalho, Nevado e Menezes (2007). Para tais autores, Arquitetura Pedagógica é uma rede de organização própria, formada por sujeitos que têm autonomia e devem se sentir motivados e compromissados com as metas do grupo, premissa básica em ações que buscam a emancipação dos sujeitos.

Partindo da concepção elaborada pelos autores, pressupõe-se que as Arquiteturas Pedagógicas são viabilizadas pela convergência "entre os paradigmas epistemológicos e as estratégias pedagógicas, acolhendo, assim, uma possibilidade de releitura dessas, demonstrando-se, mais receptivas à aprendizagem" (Carvalho, NEVADO; MENEZES, 2007, p. 39).

O intuito das Arquiteturas Pedagógicas é pensar a aprendizagem como um processo de criação de novidades, de descobertas e invenções, permitindo que os sujeitos realizem experimentações e simulações em busca de soluções para questões significativas. Nesse sentido, é possível apontar que
[...] o caráter dessas Arquiteturas Pedagógicas é pensar a aprendizagem como um trabalho artesanal, construído na vivência de experiências e na demanda de ações, interação do sujeito sobre fatos, objetos e o meio ambiente sociológico. Seus pressupostos curriculares compreendem pedagogias abertas capazes de acolher didáticas flexíveis, maleáveis, adaptáveis a diferentes enfoques (CARVALHO; NEVADO; MENEZES, 2007, p. 39).

Assim, em amplo modo, as Arquiteturas Pedagógicas podem ser compreendidas como uma proposta didática de mediação pedagógica entre os objetivos e metodologias adotadas e seu desenvolvimento em um ambiente virtual de aprendizagem. São estruturas de aprendizagem pensadas a partir da colaboração de diferentes componentes, como, por exemplo: abordagem pedagógica, softwares educacionais, internet, inteligência artificial, e, ainda, novas concepções de tempo e espaço.

Segundo os autores e de forma sintética, as Arquiteturas Pedagógicas compreendem a alteração das perspectivas de tempo e espaço para a aprendizagem, a flexibilidade em relação aos ritmos impostos pelos sujeitos que aprendem, a diversidade de fontes de recursos para a aprendizagem, a criação de novos modos de conhecer e novas formas de pensar, a expansão das capacidades individuais e grupais, novas formas de escrita e leitura coletiva, a suplantação do caráter seriado e disciplinar do currículo. Para Carvalho, Nevado e Menezes (2007, p. 34), ainda,

\section{[...] as Arquiteturas Pedagógicas funcionam metaforicamente como mapas ao mostrar diferentes direções para se realizar algo, entretanto, cabe ao sujeito escolher e determinar o lugar para ir e quais caminhos percorrer. Pode-se percorrê-los individual ou coletivamente, ambas as formas são necessárias.}

Neste contexto pedagógico, os processos de aprendizagem são vistos como um contínuo processo de ação e reflexão sobre a ação, construída a partir da vivência dos alunos. Dessa forma,

[...] as arquiteturas pedagógicas não se confundem com atividades normalmente propostas em sala de aula, voltadas para a transmissão de informações, o uso excessivo de exercícios repetitivos, em que os professores tentam educar seus alunos a partir da imposicão de atividades. Ao invés de se apoiar numa pedagogia diretiva, embasada no modelo empirista de ensino, o uso de arquiteturas pedagógicas em sala de aula pressupõe uma pedagogia relacional, em que o professor desenvolve atividades vinculadas à realidade dos seus alunos. (MICHELS; ARAGÓN, 2016, p. 267)

A partir dessa concepção e do contexto aqui descrito, este artigo procura responder ao seguinte questionamento: Quais as potencialidades $\mathrm{e}$ as limitações da metodologia utilizada nas Oficinas de Informática e Cidadania do Programa de Extensão Mutirão pela Inclusão Digital da UPF sob o prisma das Arquiteturas Pedagógicas? Tal problema de pesquisa 
ganha ênfase no momento em que se reconhece a urgência de explorar, propor e experienciar novas formas de ensinar no contexto atual, em especial em ações de extensão em uma dinâmica retroalimentada de construção do conhecimento.

\section{Metodologia}

O desenvolvimento metodológico desta pesquisa caracteriza-a como qualitativa, com viés exploratório. No que se refere à pesquisa qualitativa, Bodgan e Biklen (1994) referem que pode ser entendida como o tipo de investigação que envolve a obtenção de dados descritivos pelo contato direto do pesquisador com a situação estudada. Assim sendo, segundo os autores, a pesquisa qualitativa enfatiza mais o processo do que o produto e se preocupa em retratar a perspectiva dos participantes. Nessa direção, convergem os estudos exploratórios, que têm "como principal finalidade desenvolver, esclarecer e modificar conceitos e ideias, tendo em vista, a formulação de problemas mais precisos ou hipóteses pesquisáveis para estudos posteriores" (BODGAN; BIKLEN, 1994, p. 43).

Com tal delineamento, o campo de estudos foram as Oficinas de Informática e Cidadania oferecidas pelo Programa de Extensão Mutirão Pela Inclusão Digital, vinculado ao Gepid, na UPF, que aconteceram durante o ano de 2016, constituindo-se de encontros realizados às quintas-feiras, das $9 \mathrm{~h}$ às $10 \mathrm{~h}$ e das $10 \mathrm{~h}$ às $11 \mathrm{~h}$, com 14 alunos de quatro anos (Pré 1$) \mathrm{e}$ 17 alunos de cinco anos (Pré 2), da Escola Municipal de Educação Infantil Cantinho Feliz de Passo Fundo, Rio Grande do Sul.

Registra-se que, além da garantia do anonimato dos participantes a partir da adoção de denominação genéricas, as atividades somente foram iniciadas após o retorno do Termo de Compromisso Livre e Esclarecido, que foi assinado pelos pais dos alunos, e da autorização da escola para a realização das atividades. É importante destacar que, das $11 \mathrm{~h}$ às 11:30h, os monitores das oficinas se encontravam para avaliar como foi o trabalho do dia e apontar indicativos para o planejamento.

Assim, participantes e seus dois professores, bem como os monitores, alunos do curso de Pedagogia e Ciência da Computação da Universidade de Passo Fundo de tais oficinas constituem-se os sujeitos desta pesquisa.

Considerando a complexidade dos dados que envolvem uma pesquisa de caráter qualitativo, optouse pela triangulação na coleta dos dados primários, utilizando-se da observação direta, entrevista e questionários. Segundo Yin (2001, p. 121), “o uso de várias fontes de evidências permite que o pesquisador dedique-se a uma ampla diversidade de questões históricas, comportamentais e de atitudes".
No caso da observação, a que melhor acolhe os propósitos deste estudo é a participante, definida por Gil (2007, p. 113): "pode-se definir observação participante como técnica pela qual se chega ao conhecimento da vida de um grupo a partir do interior dele mesmo". Para os contornos deste estudo, especifica-se a condução da observação participante artificial, em que, segundo Gil (2007), o observador não pertence ao grupo, mas se integra a ele com a finalidade de obter informações.

Com tais observações, pretendeu-se registrar ações dos alunos e dos monitores frente às tecnologias utilizadas, de modo especial, a fala dos alunos e dos monitores durante as oficinas, dentre outros fatos relevantes, devidamente anotados e refletidos.

Outra fonte de coleta de dados foram as entrevistas, como já posto, realizadas com: a) monitores: com o objetivo de verificar a sua percepção frente à metodologia adotada nas oficinas; e, b) professores titulares das turmas: com o objetivo de verificar possíveis implicações das práticas vivenciadas nas oficinas no ambiente de sala de aula.

As entrevistas em estudos qualitativos, segundo Gil (2007), servem para promover um contato do pesquisador com a realidade vivida pelos atores sociais. Assim, quanto às entrevistas, foram realizadas com os monitores das oficinas e as professoras titulares das turmas, ao final da atividade de campo. O objetivo foi verificar as principais implicações da prática pedagógica vivenciada durante as oficinas, suas percepções frente à metodologia trabalhada e demais dados intrínsecos que pudessem ser revelados nas respostas, articulados com os dados obtidos com os demais instrumentos utilizados.

O questionário, por sua vez, constitui uma técnica de investigação composta por um conjunto de questões que são submetidas a pessoas com o propósito de obter informações sobre conhecimentos, crenças, sentimentos, valores, interesses, expectativas, aspirações, temores, comportamento presente ou passado (GIL, 2007).

Assim, optou-se pela aplicação de questionários aos 31 estudantes participantes das oficinas, com o objetivo de conhecer o perfil do grupo, na sua totalidade e em suas particularidades. Com tal pretensão, o questionário foi aplicado aos participantes das oficinas, no início do trabalho de campo, tendo como mote adquirir informações referentes a: idade, nível escolar, escola de origem, conhecimentos e habilidades no uso dos computadores, uso de computador em casa, acesso à internet, atividades que mais realizam no computador, dentre outros.

De posse dos dados possibilitados pela triangulação dos instrumentos, principiou-se a análise com uma leitura exploratória deles. Tal procedimento possibilitou a categorização dos dados, com base no conceito de Arquiteturas Pedagógicas, seus pressupostos e componentes fundamentais, 
estabelecendo-se, assim, três categorias de análise, cada uma organizada em subcategorias:

a) Categoria 1: Educação para a incerteza busca a solução de problemas reais, implementação da educação para a autoria, investigação e cooperação. Compreende-se, assim, as seguintes subcategorias: C1.1: Solicitação de auxílio aos monitores; C1.2: Solicitação de auxílio aos colegas; C1.3: Demonstração de habilidades para executar tarefas; C1.4: Exploração da atividade além da proposta dos monitores.

b) Categoria 2: Educação por projetos contempla o uso de prática pedagógica que fomente curiosidade e indagação. Condensa, nessa direção, as seguintes subcategorias: C2.1: Momentos de planejamento e avaliação; C2.2: Contemplação dos princípios norteadores da atividade; C2.3: Participação dos alunos; C2.4: Ações que considerem os conhecimentos prévios dos alunos.

c) Categoria 3: Ensino interdisciplinar: aborda o uso de conteúdos de diversas áreas do conhecimento. Estabelece, nesse sentido, as seguintes subcategorias: C3.1: Atividade de mais de uma área do conhecimento; C3.2: Práticas que contemplem a realidade educativa dos alunos; C3.3: Ações que demonstrem que os alunos estabelecem relação entre as várias áreas do conhecimento.

\section{Resultados}

Mesmo com delineamento qualitativo, as perguntas contempladas no questionário aplicado à amostra de pesquisa, composta pelos 31 alunos participantes das Oficinas de Informática e Cidadania oferecidas pelo Programa de Extensão Mutirão Pela Inclusão Digital, no ano de 2016, tomou caráter quantitativo, com o objetivo de caracterizar os sujeitos da pesquisa.

Assim, no Quadro 1 pode-se observar questões relativas à presença e ao uso da tecnologia computacional na vida cotidiana de tais alunos.

Quadro 1: Resultado do questionário aplicado aos alunos
\begin{tabular}{|c|c|c|c|}
\hline Total de alunos & $\begin{array}{c}\text { Possui computador } \\
\text { em casa }\end{array}$ & $\begin{array}{c}\text { Possui Internet em } \\
\text { casa }\end{array}$ & $\begin{array}{c}\text { Possui } \\
\text { computador e faz } \\
\text { uso diário }\end{array}$ \\
\hline 31 & 18 & 9 & 12 \\
\hline
\end{tabular}
Fonte: Autores, 2017.

A partir dos números do Quadro 1, é possível perceber que, embora se viva na "era digital", a presença e a utilização das tecnologias no cotidiano do grupo pesquisado são limitadas, haja vista que, dos 31 alunos, somente 18 têm computadores em casa, e desses, apenas $12(38 \%)$ os utilizam diariamente. Ainda, do total pesquisado, apenas 9 (25\%) possuem internet em suas residências.

A partir desse contexto, inicialmente pensou-se que esse fato poderia implicar de forma desfavorável no desempenho das atividades nas Oficinas. Entretanto, ao contrário, foi possível perceber que mesmo com pouca vivência cotidiana, os sujeitos demonstraram grande interesse e habilidade.

A análise, nesse caso específico, em que os alunos têm 4 e 5 anos de idade, pode referir-se primeiramente ao pressuposto de que são indivíduos capazes de adaptar-se a situações novas. De acordo com Piaget (1980), o desenvolvimento cognitivo nessa faixa etária não é linear. Desse modo, é possível incentivar a criança, "fornecendo-lhe oportunidades úteis, que o desafiem a avançar" (BRUNER, 1998, p. 55).

Dessa forma, foi possível verificar, assim, que a utilização das tecnologias fez com que os alunos pudessem colocar suas competências e seus conhecimentos em sinergia com o processo de aprendizagem, revelando-se como sujeitos ativos que transformam esse processo e que por ele também são transformados.

De modo a apresentar os dados obtidos com tais procedimentos, apresenta-se, primeiramente, os resultados da entrevista realizada em conjunto com os 4 monitores, abordando a pergunta $(\mathrm{P})$, seguida do resumo das respostas dadas (RR) e uma análise prévia do conteúdo dessas:

[P1] A escolha do tema geral a ser trabalhado nas oficinas, bem como os conteúdos e as ferramentas utilizadas foram escolhidos a partir de que critério?

[RR] O tema geral foi escolhido juntamente com as professoras e coordenadora do Projeto Transformação em Arte, levando em consideração os temas da atualidade e a realidade dos sujeitos envolvidos nas oficinas. Optou-se pela "Olimpíada Rio de 2016", com foco para a importância do esporte na construção de valores, responsabilidades, profissão, renda e saúde. Quanto às ferramentas utilizadas na educação infantil, foram escolhidos os programas Gcompris e os sites www.edinfogos.universoneo.com.br,

www.smartiklids.com.br e www.escolagames.com.br

Essa pergunta teve por mote verificar fatores inerentes ao pressuposto do conceito de Arquiteturas Pedagógicas, em especial no que se refere à sistematização metodológica. Com base nessa resposta, é possível verificar a presença de elementos que contemplam este pressuposto, e é possível perceber o conceito dos projetos de aprendizagem, a preocupação com a faixa etária dos alunos, a preocupação em fazer ligações com os conteúdos trabalhados em sala de aula e a relação desses com o tema geral.

$\mathrm{O}$ entendimento dos processos relacionados ao planejamento e à avaliação da prática pedagógica dos monitores se deu por intermédio da P2:

[P2] Existem momentos de planejamento e avaliação da prática pedagógica? Se sim, com que frequência e elementos são discutidos?

[RR] O planejamento acontece por blocos, ou 
seja, cada bloco é composto por: conhecendo, construindo e socializando. Nesse planejamento buscamos diversificar os modos com que os conteúdos são trabalhados. As avaliações acontecem semanalmente, após a oficina ou na semana seguinte, durante essa avaliação discutimos a eficácia das atividades que estamos propondo, realizando uma reflexão sobre nós mesmos e as mudanças necessárias quando os resultados não são satisfatórios, observamos a participação, o interesse, a criatividade e o envolvimento dos alunos, além de trocarmos ideias com os professores, a fim de percebermos como eles veem este processo.

O objetivo da pergunta era verificar elementos do pressuposto sistematização metodológica, porém, com ênfase nos elementos acerca da prática pedagógica. Com base nessa resposta, é possível intuir que o planejamento, além de nortear a prática pedagógica nas oficinas, funciona como mecanismo de avaliação dessa prática, possibilitando a sua transformação a cada encontro, situação que contribui para o avanço e a qualificação dos processos educativos no âmbito das oficinas.

Seguindo-se na mobilização de dados a partir do olhar e da vivência dos monitores das Oficinas, questionou-se sobre a escolha dos conteúdos e das tecnologias:

\section{[P3] A partir das escolhas dos conteúdos, você acha que seria possível realizar as atividades sem o uso das tecnologias? Se sim, como você faria?}

\begin{abstract}
[RR] Olhando para nosso planejamento, percebemos que sim, haveria a possibilidade de trabalhar sem o uso das tecnologias, porém, estas vêm como facilitadoras no processo de aprendizagem, por atraírem de maneira diferenciada para assuntos muitas vezes já trabalhados. Se não houvesse a referida tecnologia, os professores teriam de usar de um dinamismo maior para chamar a atenção a determinados assuntos. Realizamos trabalhos fora do laboratório de informática, como já mencionamos: passeios, pinturas e exercícios físicos, porém, as crianças vivem em um mundo conectado e o laboratório de informática, para elas, é um importante espaço de aprendizagem, já que alguns têm computadores em casa, mas sem a liberdade de usá-los. Quando estão na oficina, percebemos como sentem-se autores e libertos para aventurarem-se na máquina, sendo que ouvirmos várias vezes: "Profe, vem aqui que eu vou te ensinar".
\end{abstract}

A função da pergunta era verificar características das Arquiteturas Pedagógicas intrínsecas nos pressupostos concepção pedagógica forte e suporte telemático. Com essa resposta, verificou-se que a tecnologia é um meio de contemplar o novo paradigma pedagógico, é um instrumento potencializador, dinamizador e democrático. Entretanto, nas oficinas de informática, o objetivo maior é utilizar a lógica das tecnologias e não o aparato tecnológico em si.

Seguindo-se, os monitores foram questionados especificamente sobre a metodologia utilizada e os mecanismos de ação-reflexão sobre ela:

\author{
[P4] Existe estudo sobre a metodologia \\ utilizada no projeto pelos monitores? Se sim, \\ como é feito?
}

\begin{abstract}
[RR] houve um workshop interno no início dos trabalhos deste ano, possibilitando um estudo da metodologia do Mutirão a todos os monitores. Conforme nossa atuação, fomos compreendendo melhor a metodologia e realizando algumas adaptações para as crianças, sendo que esta é a primeira turma de educação infantil presente no Projeto. Estamos realizando um estudo mais aprofundado, através de leituras, observações direcionadas e tratamento dos dados, a fim de adaptarmos essa metodologia para as crianças.
\end{abstract}

O propósito da pergunta era verificar a apropriação da metodologia pelos monitores do projeto "Mutirão pela Inclusão Digital". Com base na resposta, foi possível verificar o entendimento dos monitores acerca da metodologia, estudos sistemáticos acerca da proposta, bem como a capacidade de adaptar a metodologia às diferentes turmas atendidas pelo projeto.

Em análise prévia das respostas como um todo, pode-se inferir que, a exemplo do que preconiza o conceito de Arquiteturas Pedagógicas, especificamente no que se refere à sistematização metodológica, o Programa Mutirão pela Inclusão Digital apresenta as características desejáveis. No entanto, uma análise mais completa e consistente dos resultados da entrevista com os monitores será feita após a análise prévia da entrevista dos professores e das categorias de análise.

Em sequência, contempla-se a entrevista com os professores que acompanhavam as crianças. Destacase que as respostas foram compiladas, do mesmo modo que anteriormente, abordando a pergunta $[\mathrm{P}]$, seguida do resumo das respostas dadas [RR] e uma análise prévia do conteúdo dessas. A entrevista com as professoras acompanhantes das turmas foi realizada ao término das atividades de campo realizadas durante 15 encontros, quando foi possível estabelecer algumas reflexões sobre questões relevantes acerca da relação e influência das metodologias das oficinas e das práticas em sala de aula.

A primeira questão buscou reconhecer a relação do professor e da escola com o uso e apropriação do computador e suas possibilidades:

[P1] Você já utilizou ou utiliza o computador em atividades na escola? Se sim, como e com que finalidade?

[RR] Poucas vezes, primeiro porque a escola não disponibiliza um laboratório de informática, também não temos computadores que possam ser levados para as salas de aula. A utilização apenas é feita para vídeos, em uma sala específica onde fica o computador, o aparelho de vídeo, a televisão. 
Com essa resposta, foi possível perceber que os professores ainda vinculam o uso do computador na educação ao laboratório de informática. E que na ausência dele, atividades utilizando tecnologia digital não acontecem, e quando acontecem, é em um lugar específico.

Em sequência, abordaram-se os professores que acompanharam as turmas nas Oficinas de Informática e Cidadania oferecidas pelo Programa de Extensão Mutirão Pela Inclusão Digital sobre as atividades realizadas e a metodologia utilizada nesse contexto:

[P2] Frente às atividades realizadas nas oficinas, qual sua percepção em relação à metodologia utilizada pelos monitores?

[RR] A metodologia é bem particular, é uma novidade. Embora quando estamos em sala de aula procurarmos sempre novidades e inovações, ainda dependemos de seguir um currículo e vencer os conteúdos. Nas oficinas é possível perceber que os alunos são incentivados a ter autonomia, a resolver suas tarefas, os monitores auxiliam quando necessário, mas também incentivam a realização das tarefas. Outro ponto que percebo é o trabalho de valorizacão das produções que as crianças realizam, cada tarefa realizada é tratada como uma vitória, os alunos nessa faixa etária gostam muito desse direcionamento. Consideramos muito importante o processo de planejamento das atividades, participamos de dois encontros e isso possibilitou que as atividades tivessem em consonância com a realidade educativa das crianças.

A partir dessa resposta, intui-se que mesmo não conhecendo conceitualmente a metodologia baseada nas Arquiteturas Pedagógicas, as professoras apontam para alguns de seus pressupostos, como: educar para a incerteza, desenvolver a autonomia dos alunos, ter a visão do professor como facilitador de atividades, uso de planejamento didático coerente com faixa etária e conhecimentos prévios dos alunos, entre outros.

De modo a complementar o entendimento da questão anterior, questionou-se aos professores sobre como avaliam a forma ou o método como os monitores trabalham nas Oficinas:

[P3] A forma ou método que os monitores trabalham nas oficinas pode ser utilizada em sala de aula? Se sim, como?

[RR] Se pensarmos no uso dos computadores, da internet, dos programas que são utilizados acreditamos que não, somente se pudéssemos ter um computador para cada aluno como é aqui no laboratório. Mas quando pensamos nas ações dos monitores, essas sim podem ser levadas para a sala de aula.

Com essa resposta, observa-se também uma possível vinculação do uso das tecnologias a uma determinada ferramenta, como o computador, a internet. Contudo, foi percebido pelas professoras ações dos monitores que se diferenciam da prática pedagógica exercida na maioria das escolas.
Buscando-se a compreensão das similaridades ou diferenças entre a sala de aula e ambiente do Programa, inquiriu-se os professores sobre quais atividades não poderiam ser partilhadas em ambos os contextos:

[P4] Que atividades realizadas nas oficinas você considera que não podem ser realizadas em sala de aula? Por quê?

[RR] Atividades nas quais todos os alunos precisem utilizar o computador ao mesmo tempo, pois não tem estrutura física para que essas aconteçam.

A resposta aponta para uma deficiência de infraestrutura física das escolas e para a importância de projeto de extensão na área utilizando-se a infraestrutura das universidades.

Redirecionando a compreensão para os aspectos pedagógicos, questionou-se os professores sobre a percepção de possíveis diferenças entre os alunos que participam e os que não participam das Oficinas:

[P5] Dos alunos que participaram das atividades, você notou alguma diferença em sala de aula em relação aos demais?

[RR] O que percebemos de maneira expressiva é a empolgação e motivação dos alunos em participar das atividades do Mutirão. Alguns têm demonstrado mais participação e interesse com os assuntos de sala aula, alguns também fazem comparações por exemplo: "lá no Mutirão é de tal forma, aqui é de outra". Talvez se pudéssemos seguir com o trabalho de forma sistemática certamente muitas contribuições ocorreriam.

As respostas levam a compreender que o nível de motivação dos estudantes nas oficinas é acima do comum, especialmente quando comparado com as atividades escolares.

Por fim, buscou-se entender se as atividades realizadas nas oficinas impactam na assimilação de aprendizagens específicas relacionadas ao conteúdo trabalhado nos temas/subtemas:

[P6] A partir das atividades feitas nas oficinas a respeito do tema geral do projeto, "esportes", você acha que os alunos teriam alcançado o mesmo nível de desenvolvimento sem o uso da tecnologia? Por quê?

[RR] O que percebemos é que a tecnologia permite que possamos ter mais instrumentos para incrementar as aulas. O uso de vídeos, de programas específicos, da internet de um modo geral possibilita qualificar as aulas. $\mathrm{E}$ isso possivelmente é um fator que qualifica o desenvolvimento das atividades e do aprendizado.

Com essa resposta, é possível intuir que o contato com a proposta metodológica do Mutirão levou as professoras a iniciarem uma conexão com as 
atividades realizadas e as possibilidades de utilização dessas na sala de aula. Mas, revelou-se a relevância dessas para o desenvolvimento qualitativo das aulas. Ainda, observou-se a importância do suporte telemático, premissa das Arquiteturas Pedagógicas.

Assim, de modo geral, é possível verificar, inicialmente, que as professoras relataram que a dificuldade em realizar atividades semelhantes àquelas propostas no Programa Mutirão pela Inclusão Digital deve-se, principalmente, à infraestrutura precária das escolas na área de informática. Também é possível relatar que, embora não tenha sido verbalizado pelas professoras, a existência de mais de uma pessoa para a realização da metodologia é determinante para seu sucesso.

A resposta à segunda pergunta corrobora o potencial dos projetos de extensão para realizar atividades livres da influência das demandas curriculares ou de conteúdos a serem vencidos em um determinado período de tempo. No entanto, colabora para a melhor compreensão das respostas dadas pelos monitores, em especial a partir dos dados obtidos pela observação das Oficinas, organizados de acordo com as categorias de análise.

Apresenta-se, assim, os Quadros 2, 3 e 4, que destacam, na primeira coluna, a variável dentro da referida categoria; na segunda, a quantidade de vezes que a categoria foi observada e, na terceira, uma préanálise de sua observação.

Quadro 2: Síntese da categoria de Análise 1 - Educação para a incerteza

\begin{tabular}{|c|c|c|}
\hline \multicolumn{3}{|c|}{ Categoria 1: Educação para a incerteza } \\
\hline Variáveis & $\begin{array}{l}\mathrm{N}^{0} \text { de } \\
\text { vezes }\end{array}$ & Pré-análise da observação \\
\hline $\begin{array}{l}\text { C } 1.1 \\
\text { Solicitação de auxilio } \\
\text { aos monitores }\end{array}$ & 106 & $\begin{array}{l}\text { Com grande quantidade de ocorrências, demonstra } \\
\text { a dependência dos alunos em relação aos } \\
\text { professores e monitores, característica do modelo } \\
\text { tradicional de ensino, que centraliza a autoridade } \\
\text { no professor/monitor. Pode demonstrar, também, o } \\
\text { desejo por realizar as atividades que, talvez, } \\
\text { pudessem estar aquém do que estavam habituados } \\
\text { na escola e, portanto, requisitavam mais } \\
\text { frequentemente o auxilio dos monitores. }\end{array}$ \\
\hline $\begin{array}{l}\text { C } 1.2 \\
\text { Solicitação de auxilio } \\
\text { aos colegas }\end{array}$ & 17 & $\begin{array}{l}\text { Houve poucas socializações com os colegas, } \\
\text { ficando mais frequentes as socializações e } \\
\text { interações com os monitores, o que, para a faixa } \\
\text { etária dos sujeitos de pesquisa, não é incomum. }\end{array}$ \\
\hline $\begin{array}{l}\text { C } 1.3 \\
\text { Demonstração de } \\
\text { habilidades para } \\
\text { executar tarefas }\end{array}$ & 35 & $\begin{array}{l}\text { Mesmo com acesso doméstico limitado a } \\
\text { computadores e Internet - fato que talvez tenha } \\
\text { relação com o número de ocorrências da categoria } \\
\text { C.1.1., os alunos demonstraram grande habilidade } \\
\text { com a tecnologia, estimulados pela didática e } \\
\text { metodologia dos monitores. }\end{array}$ \\
\hline $\begin{array}{l}\text { C } 1.4 \\
\text { Exploração da } \\
\text { atividade além da } \\
\text { proposta dos monitores }\end{array}$ & 17 & $\begin{array}{l}\text { Provavelmente, devido à dependência dos alunos } \\
\text { com os monitores, estes demonstraram poucas } \\
\text { ações de superação da proposta dada, se } \\
\text { propondo a atender somente o que era } \\
\text { demandado, postura comumente adotada na } \\
\text { escola. }\end{array}$ \\
\hline
\end{tabular}

Para além da análise desta categoria e a partir da experiência do projeto, é possível supor que as instituições de ensino formais parecem não desenvolver dinâmicas em que os estudantes tratem com autonomia e a partir da colaboração com os demais colegas a resolução de problemas ou impasses nascidos em processos de aprendizagem. Isto fica claro no número de ocorrências das sub-categorias C.1.1. e
C.1.2. Por outro lado, o fato de buscarem auxílio mesmo que dos monitores - parece denotar o interesse na concretização de seu processo de autoria, o que, em última análise, pode representar o resultado da aprendizagem específica.

Quadro 3: Síntese da categoria de Análise 2 - Educação por projetos

\begin{tabular}{|l|c|l|}
\hline \multicolumn{3}{|c|}{ Categoria 2: Educação por projetos } \\
\hline \multicolumn{1}{|c|}{ Variáveis } & $\begin{array}{l}N^{0} \text { de } \\
\text { vezes }\end{array}$ & \multicolumn{1}{|c|}{ Pré-análise da observação } \\
\hline $\begin{array}{l}\text { C 2.1 } \\
\text { Momentos de } \\
\text { planejamento e } \\
\text { avaliação }\end{array}$ & 8 & $\begin{array}{l}\text { Observada todos dias, pois é parte da } \\
\text { metodologia os monitores se reunirem ao final de } \\
\text { cada oficina para avaliar e planejar o próximo } \\
\text { encontro }\end{array}$ \\
\hline $\begin{array}{l}\text { C 2.2 } \\
\text { Contemplação dos } \\
\text { princípios norteadores } \\
\text { da atividade }\end{array}$ & 8 & $\begin{array}{l}\text { Observada também em todos dias, foi possivel } \\
\text { identificar que a conduta dos monitores era } \\
\text { pautada nos princípios norteadores das } \\
\text { Arquiteturas Pedagógicas. }\end{array}$ \\
\hline $\begin{array}{l}\text { C 2.3 } \\
\text { Participação dos Alunos }\end{array}$ & 123 & $\begin{array}{l}\text { Essa categoria uniu intencionalmente as } \\
\text { categorias C1.1 e C1.2, por se tratarem de } \\
\text { participações e interações do alunos. }\end{array}$ \\
\hline $\begin{array}{l}\text { C 2.4 } \\
\text { Açães que considerem } \\
\text { os conhecimentos } \\
\text { prévios dos alunos }\end{array}$ & 16 & $\begin{array}{l}\text { Ficaram visíveis as ações dessa categoria nos } \\
\text { encontros de avaliação dos monitores, discutindo } \\
\text { e considerando o aprendizado e a evolução de } \\
\text { cada aluno para preparar a próxima oficina. }\end{array}$ \\
\hline \begin{tabular}{l} 
Fonte: Autores, 2017 \\
\hline
\end{tabular} \\
\hline
\end{tabular}

Com relação à Educação por Projetos, elemento constituinte das Arquiteturas Pedagógicas, é possível apontar que, embora não tenham um nível de autonomia destacado, como é possível verificar na análise da Categoria 1, demonstraram alto índice de participação a partir do número de ocorrências da subcategoria C.2.3., o que parece ter sido favorecido pela metodologia adotada no projeto.

Quadro 4: Síntese da categoria de Análise 3 - Ensino interdisciplinar

\begin{tabular}{|c|c|c|}
\hline \multicolumn{3}{|c|}{ Categoria 3: Ensino interdisciplinar } \\
\hline Variáveis & \begin{tabular}{|l|}
$N^{0}$ de \\
vezes
\end{tabular} & Pré-análise da observação \\
\hline $\begin{array}{l}\text { C } 3.1 \\
\text { Atividade de mais de uma } \\
\text { área do conhecimento }\end{array}$ & 6 & $\begin{array}{l}\text { Visivelmente, a utilização de mais de uma área } \\
\text { de conhecimento acabou por motivar os alunos, } \\
\text { tornando mais natural o andamento das oficinas }\end{array}$ \\
\hline $\begin{array}{l}\text { C } 3.2 \\
\text { Práticas que contemplem a } \\
\text { realidade educativa dos } \\
\text { alunos }\end{array}$ & 6 & $\begin{array}{l}\text { Observada em quase todas reuniões de } \\
\text { avaliação e planejamento, essa categoria } \\
\text { mostrou fazer parte da metodologia e da prática } \\
\text { dos monitores }\end{array}$ \\
\hline $\begin{array}{l}\text { C } 3.3 \\
\text { Ações que demonstrem } \\
\text { que os alunos estabelecem } \\
\text { relação entre as várias } \\
\text { áreas do conhecimento }\end{array}$ & 12 & $\begin{array}{l}\text { Foi muito perceptível, na fala dos alunos, que } \\
\text { eles estabelecem relações entre as oficinas, os } \\
\text { conteúdos da aula a realidade do seu } \\
\text { cotidiano conectando várias áreas do } \\
\text { conhecimento e vários espaços de } \\
\text { aprendizagem. }\end{array}$ \\
\hline
\end{tabular}

A categoria 3, com o menor número de ocorrências em relação às demais, pode ter relação com o fato de que a metodologia do projeto privilegia processos de aprendizagem em detrimento a momentos de ensino em que monitores ou professores assumem a centralidade dos processos. Ainda, as modalidades dos encontros preveem um número reduzido de momentos em que os alunos refletem sobre o assunto - quando poderiam estabelecer paralelos com outras áreas e com o que aprendem na escola -, uma vez que a maioria dos encontros é destinada ao exercício de autoria utilizando tecnologias digitais. No Gráfico 1 é possível verificar o número de ocorrências em cada uma das categorias. 
Gráfico 1: Síntese da ocorrência das categorias de análise nos dados primários coletados

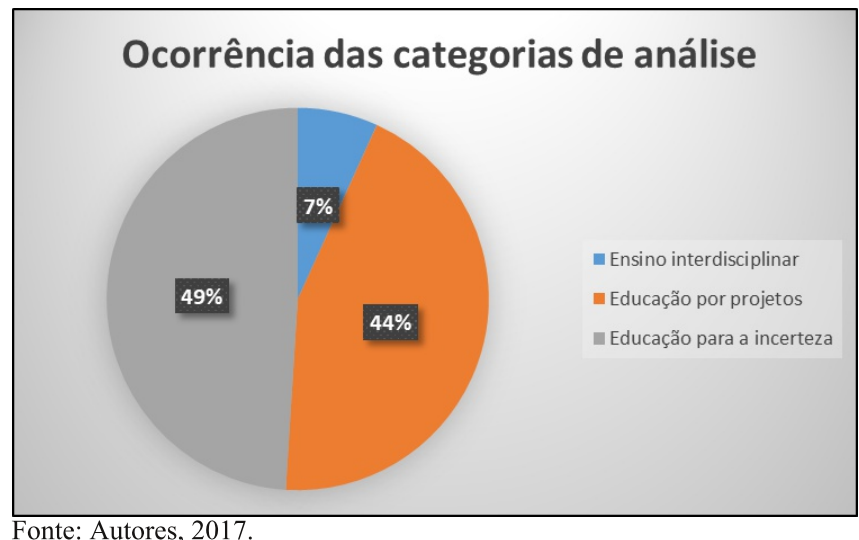

Após a apresentação e a análise prévia dos dados coletados nos questionários, entrevistas e observações, é possível realizar algumas reflexões e considerações em relação ao problema de pesquisa, retomando-se: Quais as potencialidades e as limitações da metodologia utilizada nas oficinas?

A partir do entrelaçamento do aporte teórico e da verificação empírica possibilitada pela triangulação na coleta de dados, foi possível perceber que o conceito de Arquiteturas Pedagógicas está presente em situações do contexto das oficinas do Programa Mutirão pela Inclusão Digital, nas ações dos alunos e nos momentos que antecedem às atividades (no planejamento e na prática pedagógica dos monitores). Também é notado, na didática adotada, elemento que assume uma importante dimensão no decorrer das atividades e representa um fator fundamental durante as Oficinas.

Sobre a didática, Libâneo (1994, p. 25) aponta que a ela cabe

\begin{abstract}
[...] converter objetivos sócio-políticos e pedagógicos em objetivos de ensino, selecionar conteúdos e métodos em função desses objetivos, estabelecer vínculos entre ensino e aprendizagem, tendo em vista o desenvolvimento das capacidades mentais dos educandos.
\end{abstract}

Ainda na perspectiva da prática pedagógica dos monitores, destaca-se a escolha criteriosa dos recursos tecnológicos utilizados para suporte à autoria em diversas mídias, que possibilitaram aos alunos ultrapassar a simples utilização mecânica, autorizandoos à exploração e apropriação de sua lógica hipertextual, ou seja, a participação ativa, o compartilhamento de saberes e a autoria.

Nesse sentido, outro fator que cabe destacar neste momento é que os alunos estão inseridos em contextos familiares que quase não dispõem de tecnologias digitais. No entanto, esse pouco contato e conhecimento não prejudicou o desenvolvimento das atividades, mas fortaleceu a interação com os monitores e com os demais. Para Piaget (1980, p. 18), a criança é potencializadora, dialoga com a cultura desde o nascimento. É um sujeito cognoscente, não espera passivamente o conhecimento. Tal percepção ajuda sobremaneira na compreensão das ocorrências da categoria C.1.1.

Essa característica também é destacada por Veen e Vrakking (2009) em seu livro Homo Zappiens, a partir da pesquisa realizada com 300 jovens holandeses sobre sua relação com a tecnologia. Para os autores, é uma questão de habilidade, e não de acaso. "A capacidade de busca das crianças é muito maior do que a nossa e é impossível que você consiga alcançar a mesma velocidade delas, mesmo tendo praticado por muito tempo" (VEEN; VRAKKING, 2009, p. 36).

Diante disso, foi perceptível, durante o acompanhamento das oficinas, algumas características dos pressupostos das Arquiteturas Pedagógicas, dentre as quais destacam-se: a) Ações de colaboração entre os colegas; b) Ações de investigação, explorando os diversos recursos que as ferramentas possuem; c) Atitudes de questionamentos e indagações; d) Ações de socialização durante as atividades; e) Apesar de necessitarem da presença dos monitores, realizam as tarefas com autonomia; f) Ações de interatividade com as ferramentas utilizadas; g) Realização de ligações com o conteúdo trabalhado, o que já aprenderam anteriormente e com o que aprenderam na escola.

Ainda nesse contexto, foi possível analisar a abordagem interdisciplinar dos conteúdos trabalhados e a forma de gerir os conteúdos, que oferecem aos alunos a chance de aprender a pesquisar, a relacionar, a interpretar as informações e os conhecimentos. Isso, levando-se em consideração que o conhecimento e o saber não são fragmentados, são apropriados pelos alunos nos seus processos de aprendizagem, de modo que eles estabeleçam relações entre si, possibilitando, assim, compreensões globais e críticas da realidade.

Ainda, observou-se, durante as Oficinas, a incorporação da noção de interligação de conceitos espontâneos dos alunos, que caracterizam seus conhecimentos prévios advindos de seu contato com a realidade e com os conhecimentos construídos na escola, os quais foram sempre considerados e conectados com as atividades das oficinas.

Nessa linha, as atividades das oficinas foram pensadas e executadas de forma ampla, flexível e dinâmica, em ciclos de ensino-aprendizagem, mas sempre em consonância com as atividades escolares, através do contato com as professoras titulares das turmas e do diálogo com os alunos durante as atividades, numa clara relação com uma concepção pedagógica forte, característica das Arquiteturas Pedagógicas.

Diante de tais considerações, é possível afirmar que pensar sobre uma proposta metodológica pautada na lógica das Arquiteturas Pedagógicas, dentro de um contexto escolar marcado pela perspectiva tradicional de ensino, pode tornar possíveis, inicialmente, não mudanças revolucionárias, mas experiências que permitiram refletir e propor novos caminhos e perspectivas para a educação, papel importante da extensão. 


\section{Considerações Finais}

Percebe-se que, cada vez mais, a escola vem perdendo o seu status de mantenedora absoluta do conhecimento, ficando evidente a necessidade de se repensarem as propostas didáticas que vêm sendo desenvolvidas em sala de aula. Por consequência, para que os alunos, nativos desse contexto tecnológico, não percam o interesse pelo conhecimento que é produzido na escola e possam, de fato, estarem preparados para usufruir deste contexto tecnológico.

Assim, é fundamental que se destaque que, embora os ambientes educacionais tenham passado por movimentos de informatização, os recursos tecnológicos disponíveis ainda se apresentam como limitadores de iniciativas mais prospectivas e protagônicas envolvendo tecnologias. Adicionalmente, e ainda mais importante, aponta-se que a formação docente na área de informática educativa, somada à concepção de educação centrada no professor, suportada por metodologias verticalizadas e rígidas, impedem a realização de processos educativos centrados no aluno e baseados na criatividade e na inovação.

Desse modo, as ações de extensão das universidades permitem a experimentação de alternativas de formação que a escola, por sua infraestrutura, lógica e normativa, não pode oferecer a seus alunos, especialmente quando se trata da apropriação de tecnologias digitais. Longe de caracterizar-se como paliativas, as propostas de atividades diferenciadas em programas de extensão como o "Mutirão pela Inclusão Digital", ao assumirem a tríade Ensino - por conta da participação de licenciandos, Pesquisa - em função de servir de locus privilegiado de investigação, e, por fim, Extensão - a atividade em si, podem, a médio prazo, ter desdobramentos positivos sobre a formação docente nos cursos de licenciatura.

Dessa forma, a partir dessas reflexões e atendendo diretamente ao objetivo deste texto, apontase que a metodologia das Oficinas de Informática e Cidadania do Projeto "Mutirão pela Inclusão Digital" está em convergência com o conceito das Arquiteturas Pedagógicas, em especial no que tange à Educação por Projetos e para a Incerteza, sendo uma alternativa potente de transformação social, por meio de atividades de extensão da Universidade na comunidade em que está inserida.
CARVALHO, Marie J. S.; NEVADO, Rosane; MENEZES, Crediné $\mathrm{S}$. Aprendizagem em rede na educação à distância: estudos e recursos para a formação de professores. Porto Alegre-RS: Lens, 2007.

FOLHA DE SÃO PAULO. Educação: Só 1 em 10 alunos está satisfeito, e maioria pede tecnologia nas aulas. 22 set. 2016. Disponivel em: $<$ https://goo.gl/5qTyfN $>$. Acesso em: 30 set. 2016.

GIL, Antonio Carlos. Métodos e técnicas de pesquisa social. 5. ed. São Paulo: Atlas, 2007.

LIBÂNEO, José Carlos. Democratização da escola pública: a pedagogia crítico-social dos conteúdos. 3.ed. São Paulo: Edições Loyola, 1994.

MICHELS, Ana Beatriz; ARAGÓN, Rosane. Arquiteturas pedagógicas no processo de empreender: do fazer ao compreender no contexto da educação a distância. RIED. Revista Iberoamericana de Educación a Distancia, v.19, n.2, p. 263-281, 2016. doi:

http://dx.doi.org/10.5944/ried.19.2.14738

PIAGET, Jean. O raciocínio da criança. Rio de Janeiro: Record, 1980.

VEEN, Wim; VRAKKING, Bem. Homo Zappiens: educando na era digital. Tradução de Vinicius Figueira. Porto Alegre: Artmed, 2009.

YIN, Robert K. Estudo de caso: planejamento e métodos. Trad. Daniel Grassi. 2. ed. Porto Alegre: Bookman, 2001.

\section{Referências}

BODGAN, Roberto C.; BIKLEN, Sari K. Investigação qualitativa em educação: uma introdução à teoria dos métodos. Portugal: Porto Editora, 1994.

BRUNER, Jerome. A cultura da educação. Porto Alegre: Artmed, 1998. 